\title{
A DISCUSSION OF ETHNOGRAPHIC RESEARCH METHODS AND THEIR RELEVANCE FOR TRANSLATION PROCESS RESEARCH
}

\section{SEVERINE HUBSCHER-DAVIDSON}

\author{
School of Languages, University of Salford \\ Salford, Greater Manchester, M5 4WT, United Kingdom \\ Phone: +44161 2953666 \\ E-mail: s.hubscher-davidson@salford.ac.uk
}

\begin{abstract}
:
Key words: translation, ethnography, process studies, methodology, grounded theory
\end{abstract}

\section{INTRODUCTION}

Today it can be claimed that Translation studies (TS) is an interdisciplinary field by its very nature. Recent publications in the field (Hermans 2002; Inghilleri 2005; Wolf \& Fukari 2007; Papavassiliou 2007) attest to an increasing incorporation of theories and concepts from neighbouring disciplines into the study and practice of translation. The increasing emphasis and focus on the need for TS to welcome and integrate ideas from other cultural traditions and to enlarge translation by investigating new ways of thinking about this young discipline is summed up very clearly by Tymoczko (2007:19/185) when she argues that any perspective is only one way of looking at translation, and that unless TS scholars re-evaluate how research is conducted in the field and explore alternate models of translation, exciting investigations about translation will be conducted outside the field, for example by cognitive scientists and sociologists.

Research of a psychological and sociological nature in particular has gained a lot of ground in TS publications over the last few decades. Process research has developed to incorporate underlying principles and methods from cognitive psychology (Linke 2008; Hansen, Chesterman \& Gerzymisch-Arbogast 2009), for example, and elsewhere a number of researchers have attempted to redefine TS principles by conceptualizing a general sociology of translation (Hermans 2007; Gambier 2007). Resulting dynamic sociological and psychological discussions of translation have led to innovative and stimulating research that has pushed the boundaries of the discipline, and it is therefore felt by many TS researchers (Wolf \& Fukari 2007; Tymoczko 2007) that further engagement with other disciplines is warranted. According to Chesterman (2007:171), a sociological approach could help to unify the discipline, and process researchers such as Laukkanen (1996) and Jääskelainen (1999) 
have suggested that further research bridging the fields of Translation studies and Psychology is also both necessary and desirable.

In an effort to bridge cognitive psychology and TS, an increasing number of process researchers (Jakobsen 2003; Hansen 2005; Angelone 2009) have employed keyboard logging tools, eye-tracking equipment and other technologically advanced methods to analyse the translation process. According to Hansen (2008), keyboard logging tools such as Translog enable the monitoring of translation processes in ecologically valid and objective ways, as data can be quantified and therefore analysed relatively objectively. Some of the findings resulting from studies carried out in this way have been striking (e.g. Tirkkonen-Condit et al (2008)) and have enabled a deeper understanding of translator behaviour and aspects of decision-making. It has therefore become quite clear in recent years that investigating the translation process with technologically advanced methods can reveal interesting information - cognitive, behavioural etc. - about translators, and their relationships with source and target texts.

In addition, a number of researchers (Tirkkonen-Condit 1997; Jääskeläinen 1999; House 2000) have shown that much can also be learnt by adopting a more personal (and perhaps less mechanical?) approach to the study and development of translator behaviour. As this paper will aim to show, quantitative process research methods, for example, can also be merged with qualitative methodologies drawn from disciplines such as sociology and anthropology in order to enhance our understanding of what underlies the translation process. Hansen (2008) has acknowledged that a combination of both quantitative and qualitative data can be useful and, clearly, there are a myriad of ways to approach the study of behaviours and to present data. The research community can be seen as a broad church, and the particular church chosen by a researcher will largely depend on his/her own values and beliefs, and which epistemological position he/she is most sympathetic to. Nonetheless, recent trends in process research seem to have largely revolved around eye-tracking, keyboard-logging and screen recording technologies. Think Aloud Protocols are being scrupulously transcribed, charted, segmented, and pauses and utterances are converted into impressive graphs (cf. Jakobsen 2009; Immonen 2009). In the following sections I will argue that, alongside this quantitative approach, it may be useful for translation process researchers to consider employing ethnographic methods that could perhaps better tap less tangible aspects of the translation process, such as visualisations or emotional and intuitive behaviours. This would of course be dependent on the nature of the research, and ethnographic methods may of particular interest to those process researchers aiming to understand visualisations, emotions etc. specifically, 
but it could also be argued that ethnography would provide other process studies with ways to obtain richer data.

\section{ETHNOGRAPHY AND TRANSLATION STUDIES}

For many Translation studies scholars, ethnography is not a new field of study. A search for the keyword "ethnography" in the John Benjamins Translation studies Bibliography produces a list of 65 entries, amongst which contributions by Kate Sturge (1997, 2006, 2007), Hélène Buzelin (2004, 2007a, 2007b) and Michaela Wolf (1997, 2002) are most prolific. These entries attest to the many attempts made by scholars in TS to make use of what ethnographic theory has to offer.

Sturge (2006, 2007) for example, has undertaken research into how ethnological museums translate cultures through the collection of ethnographic objects. Anderson (2003) has discussed how ethnographers become translators of culture, and how they represent societies and cultures through the act of writing, thereby performing and constructing ethnography through translation processes (2003:390). Valero-Garces (1995) has also drawn parallels between the roles of ethnographers and translators as interpreters of cultural experiences. Herzfeld (2003) and Saler (2003) discuss ethnography within a broader anthropological research context, where translation is utilised (or not) for the understanding of local discourses of researched populations. In her 1997 article, 'Translation Strategies in Ethnography', Sturge also explores how the translation of ethnographies can affect power relations between cultures involved. In these interesting and valuable studies, an ethnographic perspective on translation is taken and institutions, translators and/or ethnographers are generally seen as producers of ethnographic narratives. Many of the concepts discussed in these studies draw on key ethnographic principles discussed later on in this article, such as multiplying voices and including a high dose of self-reflection. These can, I will argue, also usefully be applied to the field of translation process research. However, this paper offers a different perspective to the above-mentioned studies in that, rather than viewing the translator as an ethnographer or vice versa, it will consider how the translation process researcher can benefit from employing ethnographic methods in his/her work.

To my knowledge, Kaisa Koskinen $(2006,2008)$ is the only Translation studies scholar to have discussed and applied an ethnographic approach to the study of translators. Her recent research into translators and translated texts in the European Commission goes beyond mere discussions of "ethnography as a discipline or [...] metaphor for translation" (2006:111), and makes use of ethnography as a method for studying translators in their own specific contexts. Koskinen explores the usability of ethnographic methods for analysing the field of 
professional translation and the translators' roles and positions within it, and provides insights into how ethnographic methods can fruitfully be used to study a specific phenomenon in Translation studies. This paper aims to support Koskinen’s observations, and extend the reflection to encompass another aspect of Translation studies, e.g. to consider the potential of ethnographic methods for a better understanding of cognitive and behavioural aspects of the translation process.

\section{THE LINK BETWEEN ETHNOGRAPHY AND PROCESS RESEARCH}

Ethnography can be thought of as broadly driven by the idealist notions that 1) human understanding consists of more than what can be derived from empirical observation available only through our senses, and 2) that social actors should be allowed to speak for themselves (Kant 1781). These notions dictate an alignment with the interactionist argument that it is only through really understanding the beliefs and meanings of individual actors that we can explain why they act the way they do, and that it is therefore necessary to use research methods which offer a way of gaining insight into the beliefs and meanings that people hold (Goffman 1968). Broadly governed by these paradigms, ethnography is a form of research focusing on the sociology of meaning, and often considered a sub-discipline of sociology and/or anthropology. Ethnographic research is characterized by the reflective role of the researcher and the use of mainly qualitative data collection methods, such as interviewing and observation. Ethnographers attempt to get inside social worlds and understand these through the eyes of research participants in order to provide explanations and descriptions of these worlds in all their richness, complexity and specificity (Hammersley and Atkinson 2007).

The benefits of applying an ethnographic approach to process research therefore seem evident, especially when considering the kinds of data generally involved in process research: verbalizations, texts, researcher's field notes, to name a few. In an article extolling the benefits of ethnographic research for social psychology, David Snow (1999:97/98) suggests that "with this approach, the researcher attempts to access the actual social contexts and life worlds of those being studied", and that "the primary objective is to secure an up-close, firsthand, intimate understanding of [...] issues or processes of interest, particularly as they are experienced and understood by the individuals studied”. According to him, ethnographic research is warranted as it "illuminates basic processes difficult to access via other methodologies”. In their continual quest to gain a better understanding of, and access to, issues and processes as experienced by translators, process researchers in translation studies could certainly consider an approach claiming to provide them with an intimate understanding of these processes. 


\section{ETHNOGRAPHIC RESEARCH METHODS}

Far from presenting the researcher with rigid research frameworks and designs, ethnography allows for flexibility and complexity in research design: multiple sources of data, multiple methods to analyse these, multiple settings, timeframes etc. (Koskinen 2008:36). When an ethnographic approach to a study is taken, data may be collected via a vast number of ways, such as interviews, observations, participation etc. According to Koskinen (2008:89) "each method offers a particular vista to the phenomenon under investigation [...] each research process thus calls for reflecting on what remains unexamined.”

Koskinen (2006:114) argues that ethnographic methods can, amongst other things, "support theory building” in TS "by providing methods for eliciting new kinds of qualitative data on the social aspects of translation". She suggests that empirical work that is based on ethnography and fieldwork methods could "perform a strategic function in TS" (2008:38), and that a qualitative, data-driven approach can support theory-building of social, cultural and descriptive aspects of translation studies. It can be argued that the approach could also support theory-building of behavioural, cognitive or other aspects of TS, and that therefore ethnographic methods can have relevance for a wide range of research aims. Buzelin (2007a) also supports the development of theory resulting from ethnographic enquiry: "Ethnography rests, ultimately, upon an epistemology that is essentially inductive in nature, viewing the object in such a way as to allow the emergence of new questions and new categories that exceed pre-constructed oppositions.” (2007a:143) The focus on employing methods that produce detailed and generally qualitative data to build general principles from, although far from ground-breaking, does allow for what Koskinen (2008:2) terms "contextualised and situated observing” which can accommodate complexity and contradictory evidence in produced data. As Hammersley and Atkinson aptly put it, "the social world - and therefore our data - is complex in its enactments” (2007:155) and, as TS process researchers know only too well, it can be a challenging task to shed light on often confusing, contradictory or seemingly nonsensical data. By taking into account different perspectives, and allowing for multiple interpretations of data, ethnographic research is flexible and may therefore enable process researchers to better highlight inconsistent and differing patterns and trends in their data.

In translation process research, the use of interviews and/or traditional monologue and dialogue Think Aloud Protocols (TAPs) could easily be adapted to integrate principles and theories from ethnography. A variation on the traditional dialogue-TAPs, for example, could integrate concepts pertaining to the commonly-used ethnographic method of interviewing, 
and thus morph into a new interview-TAPs methodology. Although employed by relatively few process researchers (Fraser 2000; House 2000; Séguinot 2000), dialogue-TAPs and joint translating have been said to help bring consciousness to the fore (House 2000). Séguinot (2000) argues that dialogic studies reveal thought processes not always directly related to the task of translating, and it could therefore be beneficial for process researchers to further explore these methodologies, to approach their use from a different angle.

Recently, Hansen (2008) has argued that when dialoguing with translators, it is the investigator's role to initiate shifts, ask questions or instigate further explanation. In ethnography, there is a general tendency to move away from positivist and traditional ways of conducting research, where researchers and 'subjects' are necessarily distant, and the power remains with the researcher who is leading the interaction. In contrast, both parties are encouraged to equally share information, initiate discussions and ask for clarifications. Ethnographic researchers entering an interviewing situation are encouraged to prepare a general list of issues to cover, but the approach remains very flexible, reflexive and conversation-like, and the discussion is mutually structured between participants (Hammersley and Atkinson 2007:117). As interviews are particularly useful in gauging participants’ perspectives, discursive strategies and psychological dynamics (op cit:97), using flexible interview-TAPs in process research could be a fruitful way to investigate aspects of translator behaviour and decision-making. In the following section, a discussion of a selection of ethnographic principles and their relevance for translation process research will be discussed, along with an indication of how process researchers could make use of interviewTAPs as a methodology to put some of these principles into practice.

\section{SOME ETHNOGRAPHIC PRINCIPLES AND THEIR RELEVANCE FOR TRANSLATION PROCESS RESEARCH}

\subsection{Grounded theory}

The concept of grounded theory was first used by Glaser and Strauss in 1967. They defined it as a way to develop a theory from data, and it is therefore sometimes called data-driven grounded theory (Hammersley and Atkinson 2007). According to Hammersley and Atkinson (2007:159), ethnographic research is directed towards the generation of theory, an emergent theory which is developed out of data collection and analysis. In short, theory is generated inductively, and derived from participants' actions and verbalizations. As opposed to research that tests a pre-existing theory or hypothesis, grounded theorizing implies that theory is built up from the data itself. However, although the approach diverges from the traditionally scientific and positivist approach of hypothesis-testing, it does not entirely align itself with 
the naturalist data-driven approach which consists of providing thick descriptions of collected data and presenting these as representations of reality. As Hammersley and Atkinson argue (2007:15) both positivism and naturalism "assume that it is possible [...] to isolate a body of data uncontaminated by the researcher". In contrast, ethnography recognizes the importance of reflexivity and the researcher's role as a participant in the research process (this issue is further developed later on in this article). The researcher's influence on the study forms part of the collected data and is an integral part of the analytical process and subsequent development of theory.

According to Charmaz (2006:5) one of the defining components of grounded theory is the simultaneous involvement in data collection and analysis. In ethnography, data are seen as material to think with, and concepts are developed from this data. Grounded theorists follow leads found (op cit: 17) and reflection is undertaken between and within instances of data collection. Although sustained simultaneous data collection and analysis is recognized as a difficult enterprise, working with the data in this way is at the heart of grounded theorizing (Hammersley and Atkinson 2007:159/160) and leads to a labelling of concepts and subsequent categorizing of phenomena from the data, which enables an exploration of the relationships within that data, and the subsequent development of theory. By building reflection into different stages of their fieldwork, process researchers in translation studies can progressively focus their enquiry, and perhaps better capture contextually-relevant aspects of the data. If using interview-TAPs, the participant-researcher would for instance be required to leave sufficient time in between interviews for reflection on the significance of the data and implications for collecting further data.

\subsection{Multiple voices}

Ethnographers believe that adopting an insider's perspective increases the researcher's understanding of a phenomenon, and they argue that close involvement with the complex, contingent and local social world from which this perspective emerges is what enables the researcher to adequately analyse it (Hammersley \& Atkinson 2007). The idea that process researchers could become closely involved in the phenomenon under study may seem a surprising idea, if not an outright undesirable one for proponents of objectivity as a positive value of empirical research. However, "Looking at things "from the actor's viewpoint" should not mean being complacent nor loosing critical distance once and for all." (Buzelin 2007a:144) Translation studies process researchers can aim to get closer to understanding translators' perspectives and obtain valuable information about their attitudes and behaviours 
beyond that which is tapped into through traditional TAPs, key-stroke logging, screen recording or eye tracking.

As still relatively few studies have focused on translators themselves, their perspectives, emotions, reactions and feelings when bridging cultures and people through the act of translation, although there is increasing recognition in the field of the importance of understanding translator behaviour (see for example publications by Englund Dimitrova and Wilss), it can be argued that there is a real need to design studies that will bring translators' perspectives to the fore, that will give them a voice, and thus involve them in the study of themselves. Process researchers aiming to understand translators' perspectives and intentions, how these shape their behaviours, and how translators reflect on the situations they face and how they see themselves, would undoubtedly benefit from adopting an approach which encourages meanings to be discovered via a joint process, where participants' own views of their relationships with texts and with the entire translation activity are given due attention.

Koskinen (2008:10) encapsulates this principle when she speaks of a "conscious refusal to force a unified perspective on the object under study”. In her study, Koskinen obtains translators' own views of their role as EU translators with the means of focus group discussions, and Sturge (2006:437) proposes the inclusion of 'native voices' in Horniman labels so as to undermine the authority of the western museum as a cultural translator. Likewise, it can be argued that translators' voices need to be included in translation process research. Doing so would not only minimize the singularity of the researcher's voice but, perhaps in the same way that an audience in a museum should be allowed to view objects on their own terms, without the presence of labels (Sturge op cit), scholars should be able to interpret process research data without the 'presence' of the researcher, and translators should be allowed the freedom (the right?) to contribute to knowledge creation that directly or indirectly involves them. Although the idea of translators contributing to the interpretation of their own behaviours may seem unpalatable to some, it could be said that their voices, heard or unheard, are present regardless and should be therefore be included in the study of translation processes. In the same way, the process researcher's voice is also necessarily present and could be further acknowledged in translation studies. The use of interview-TAPs (with all the ethnographic principles entailed) could allow them to experience for themselves, and become a part of, the world they study, which would be a useful step towards recognising this presence. The role of the ethnographer as a reflective practitioner is developed later on in this paper.

Although the need to include multiple voices in the research process may seem evident to social researchers, it is still rarely acknowledged in empirical investigations. In her studies, 
Wolf (1997, 2002) discusses the unequal power relations that exist within research, and suggests that ethnographers who undertake fieldwork have tremendous power in how the data is written up (1997:128). The argument can be extended to encompass translators as they also have a major responsibility in the sense that readers have no access to the originals, and to process researchers who are also responsible for producing narratives and meanings to be received by potential readers. Koskinen (2008:56) chooses to inscribe herself in her text in an attempt to counterbalance a power structure in which she, as the researcher, used her position to define the object of study and, in the field of cultural anthropology, the authority of ethnographic texts and their modes of writing were severely questioned in the 1980s, thus leading to the drafting of more open and 'messy' ethnographic texts combining different writing styles and viewpoints to better reflect the complexities of social life (Hammersley and Atkinson 2007:203/4).

In his study, Blommaert (2005) sheds light on the unequal power relations that exist and persist through the production of texts. He describes how Belgian asylum authorities speak the story of asylum seekers through a regimented text trajectory which contains numerous interventions by various actors, and where the asylum seeker's voice is absorbed and appropriated with the result that "most of what we read in the text is a summarized version of the applicant's story, framed in a metapragmatic evaluative grid that casts doubt on or disqualifies episodes, fragments or the whole of the story" (2005:221). Blommaert goes on to suggest that the encounter is a highly specific event in which the conditions and expectations are not necessarily equally well understood by both parties (Maryns 2004, in Blommaert 2005). Just as the process of writing down these encounters is said to subjectify participants in the Foucauldian sense (op cit) it can also be argued that the process researcher's (or indeed any researcher's) own articulation of events (in conferences, in research articles etc.) can subjectify participants in a similar way, as scholars generally provide a summary, analysis, or interpretation of an event by means of the discursive conventions of accepted academic language.

Blommaert (2005:229-233) takes up Inghilleri's argument (2003) that routine, institutional patterns of behaviour become practices that organize discourse, and convert it into another discourse during which the participant loses his voice. In the same way as translators negotiate the linguistic and cultural differences between the source language and culture and that of the target audience for the translation (Rubel \& Rosman 2003:11) a researcher has to negotiate between the world of participants and that of his own readership. This journey, where information is interpreted and written with a specific audience in mind, can be particularly problematic for TAPs researchers when pages and pages of charted and 
encoded segments of verbalized protocols have to be analyzed by the researcher, sometimes months or even years after fieldwork was undertaken. It could therefore be envisioned that participants be asked to comment on the researcher's notes, or even to produce a reflective analysis of their own behaviour. This would serve to redress the balance somewhat and produce discourse that is the result of "reciprocal, joint, dialogic and polyphonic processes" (Wolf 1997:130).

The ethnographic concept of reciprocity was also applied by Buzelin (2007a). Participants in her ethnographic research on translators and publishers of literary fiction were asked to read her research before it was published, "so that they could ensure it is not detrimental to their interests" (2007a:145). She acknowledges that this has enabled her to fine-tune her account and further develop particular points. Koskinen (2008) also asks participants to provide feedback during the analytical phase of her study. However, to my knowledge, this method is not widely-used or discussed by translation process researchers, however competent they might be at interpreting behaviours. Wolf (1997:131) suggests that the "competence of ethnographers as well as of translators [is] increased if the ethnographic result (the translated text) is discussed and negotiated with the researched subject (the author of the original text)". Surely this point is equally valid when applied to translation process research.

\subsection{The reflective practitioner}

The last ethnographic principle that I would like to discuss in relation to process research is reflexivity, and what form this takes in ethnographic research.

Koskinen (2008:55) argues that "in translation studies, we do not have many explicit discussions on the complexities involved in the dual role that many scholars in the field have as previous practicing translators and/or interpreters.” Because many translation studies researchers are studying a profession or activity that they took part in at some point, this necessarily raises important questions regarding their relationship to the study. Koskinen crystallises this issue in her study when she asks: 'as a scholar, can I trust myself as a translator?' (2008:9) Process researchers could therefore also usefully reflect on their ability to interpret translator and interpreter behaviour.

Ethnographic research accepts that researchers are part of the social world they study, and therefore recognizes inherent reflexivity in research. According to Hammersley and Atkinson (2007:19) reflexivity has been given increasing attention by ethnographers in recent years: 'By including our own role within the research focus [...] we can produce accounts of the social world and justify them' (Hammersley and Atkinson 2007:18). In her study, Koskinen 
(2008:51) acknowledges that there are issues of deconstruction/reconstruction of identities and personalities to take into account, and it would be difficult to argue that process research avoids these issues entirely.

As previously argued, one of the implications of being a reflexive ethnographer or process researcher is the need to analyse one's relationship to the study in question. In order to approach this complex issue, it is useful to consider the various roles that the ethnographic researcher has to adopt in a given research setting. As Hammersley and Atkinson argue (2007:64/82), the researcher may adopt various roles during the fieldwork which do not necessarily coexist peacefully, but which are laden with implications for the research itself.

Buzelin (2007a:145) maintains that "the work of collecting data presupposes a relationship of confidence. This confidence is never a given but, rather, must be established and sometimes redefined as the research continues”. In ethnographic research, it is often the case that the researcher morphs into a participant alongside subjects, so as to build this relationship of confidence: taking on the role of a participant, whilst also being an observer, is considered necessary in order to become "one of the gang” (Koskinen 2008:54), but also to reduce the risk of misinterpreting behaviours. It can also be argued that partaking in TAPs, interview-TAPs, or other similar translation experiment alongside translators would facilitate data production as participants may feel more comfortable discussing or commenting on an activity that the researcher had also undertaken, or was also taking part in. If using the lingua franca of the researched population is deemed essential in ethnographic research in order to understand the nature of the local culture and its meanings (Rubel \& Rosman 2003:3), so the process researcher will be more apt to understand meanings of behaviours if $s /$ he is immersed in and uses the translators' 'local' language.

It is deemed important for the ethnographic researcher to fully participate in his/her study, and thus move away from the constraints of being seen as a researcher. In the same way, process researchers may need to discard their role as trainer, lecturer and/or researcher. The transformation into a fully-fledged participant can be both physical and psychological: physical in the sense that one's personal appearance can be altered (something Hammersley and Atkinson (2007:65) refer to as 'impression-management') and psychological because the role change entails different ways for the researcher of thinking about and discussing the situation and/or activity. In the case of a translation being discussed during an interviewTAPs session for example, it may be necessary for both student and researcher to 'just' be translators.

Koskinen (2006:116) highlights the benefit for the researcher of being in this unique position: "Because of its fundamental situatedness, ethnographic research opens up a range of 
possible researcher positions [...] It therefore offers systematic ways of capitalizing on the practical experience of the translation scholars." It might be said that for process researchers, this situation offers ways of capitalizing on their own practical, personal, emotional and cognitive experiences, but also, by extension and as a result of their 'metamorphosis' into a participant, on that of their researched population.

Clearly, being a reflective/reflexive practitioner is no simple task. Junker (1960) and Gold (1958) suggest that while adopting a participant role, the ethnographic researcher is also observing the interactions with awareness of the experiment's aims and objectives. Therefore, more than simply participating, or observing, the ethnographer often adopts the triple role of participant-observer-researcher. The challenges involved in this are numerous: unrealistic expectations, difficulty in suspending preconceptions, or in accepting a novice role, experiencing a culture shock, maintaining optimum data collection conditions etc. (Hammersley and Atkinson 2007:81-85) Far from straightforward, the roles adopted by the ethnographic researcher shape the study and, as Hammersley and Atkinson suggest, the researcher is sometimes both insider and outsider, "poised between familiarity and strangeness", and "a balancing act may [then] need to be achieved between these roles, and that of someone who is unacceptably ignorant.” (2007:64/89) A possible solution for the researcher is to move among roles within a research setting to avoid this marginal feeling, and to maintain intellectual distance. Due to the difficult positions and viewpoints necessarily adopted by the ethnographer-researcher in the pursuit of data, and the influence of these on the kinds of data collected, it becomes necessary for the researcher to actively engage in reflection on his/her motivations, expectations, feelings etc. According to Koskinen (2008:53-55), being self-aware and conscious of one's engagement in the research process may seem self-indulgent, but she argues that researchers in translation studies would benefit from adopting a reflexive approach to shed light on the complexities involved in taking on the dual role of translator/researcher. In the case of process research, it is equally important for the researcher to think about his behaviour and attitudes in terms of a potential translation task undertaken as a participant, but also as a researcher in relation to the wider study.

The continuing ambiguity that colours the entire research process has to be somehow acknowledged and made visible [...] This ambiguity cannot be held back in the hope of acquiring an aura of increased objectivity, but it can be productively used to benefit the analysis. (Koskinen 2008:55)

\section{OTHER CONSIDERATIONS}


As briefly discussed in the previous section, employing ethnographic research methods presents its own challenges. As with other approaches, the research process can be affected by a number of factors, such as the balance of power between participants, the influence of context on data produced, and general trustworthiness of produced data.

One of the often cited drawbacks of ethnographic research is the use of relatively small samples of participants, which means that findings are not easily generalisable. Because of the complex nature of ethnographic research and its emphasis on the situated, detailed and experienced aspects of reality, the focus is often limited and, as Koskinen (2008:7) suggests, microscopic. Although detailed analyses of small samples can be revealing in themselves and "increase our understanding of the larger whole" (op cit) it is still necessary to be cautious. It is nonetheless interesting to note that Bourdieu, a proponent of ethnography, suggested that "single cases, even if they don't speak to the totality of the population or the system, can speak to theory” (in Bloammaert 2005:228).

Closely linked is the consideration of generalisability of findings. Kate Sturge (2006:433) acknowledges the problematic nature of written ethnographies when referring to the drafting of object labels in museums. She notes Fabian's reference to "the way written ethnography asserts general truth by occluding the specificity of the ethnographer's experience”. If using ethnographic methods, one must take great care not to translate personal experience into universal statements of truth. Rubel and Rosman (2003:5) highlight the risks in developing analytical concepts in anthropology as this entails the making of generalizations, thus obscuring some of the individuality and specificity of cultural phenomena.

Nonetheless, Hammersley and Atkinson (2007:97/120) suggest that participants' accounts can still be valid and useful in terms of the perspectives they imply and the psychosocial dynamics they suggest, and that there is no such thing as pure data. Although it is important to bear in mind the context-bound nature of any experiment, it is perhaps useful to adopt the naturalist stance that social reality and phenomena can still be appreciated and described for research purposes. Blommaert (2005:228) when reviewing Bourdieu's take on ethnography suggests that he "accepted it in its fullest sense, including the inevitable quagmires of subjectivity, bias and 'doing-as-if' in the field”. It can therefore be argued that, armed with this knowledge, translation process researchers can make efficient use of ethnographic research methods to increase their understanding of translators' perspectives and behaviours.

\section{CONCLUDING REMARKS}

In this paper, I have discussed the potential of ethnographic methods for a better understanding of various aspects of the translation process. Injecting a dose of ethnography to 
empirical studies in particular could perhaps contribute to providing translation researchers and participants with what Tirkkonen-Condit terms "empowering experiences" (2009) that will open their eyes.

The relevance of ethnography for translation process research is evident, if only because researchers in both fields are interested studying a specific population. The suggested use of ethnographic interviews, or interview-TAPs, in translation process research would encourage a more flexible and natural approach to the study of translator behaviour than traditional methodologies. The continual reflection on processes, perspectives and points of interest inherent in ethnographic research invites an open approach to the research, and enables the investigation of very rich data, not easily accessible otherwise.

Hammersley and Atkinson (2007:170) argue that we can understand talk only as it is involved in action, and perhaps it also holds true that we can only understand action as it is involved in talk. In addition, it might be that researchers can only fully understand an activity if they undertake it as a participant, and thus experience for themselves the process that they are studying. Koskinen sums this up clearly: "Ethnography, with its tradition of self-reflexive research and discussions of ethical codes of conduct, helps you become aware of the fundamental questions of both who you are and where you stand in the research project, and who those you study are and what their position is”. (2006:114)

Clearly, the trustworthiness of verbalizations is an ongoing debate in the field of translation process research (e.g. Li 2004), and it would be naive to assume that methods such as interview-TAPs avoid the issue. Nonetheless, the inclusion of reflexivity in the research process, and acknowledgment of the various perspectives and influences involved in the research, goes some way towards enhancing our understanding of the complexity of social life, of translators' behaviours and identities. In addition, other ethnographic methods could be employed. Koskinen's observation that group interviews and focus group research are not as commonly used as one might expect in ethnography (2008:83) is also pertinent for translation studies, and may provide an avenue for further research in process studies in particular. If, as Buzelin (2004) suggests, translators translate what they recognise in a text, and therefore what they already know, thus providing the reader with an interpretation, it could also be argued that process researchers provide their readers with their interpretations of what they recognise in an experiment. Taking part in ethnographic focus groups, group interviews as well as interview-TAPs, may encourage translation researchers to think about the translation process from a new perspective, and as an expression of myriad complex negotiations. 
In future, it is hoped that more ethnographic accounts will be produced of translators' experiences and behaviours based on a combination of researchers' and participants' reflections and interpretations. Connections could then be made between findings produced with a large number of diverse sources of data from different process studies, something typical of integrative ethnography. Although "ethnography is not an easy choice for a researcher [...] addressing issues arising from real life can enhance the researcher's feelings of meaningfulness.” (Koskinen 2008:154-155) Further engagement with the discipline of ethnography would therefore seem a particularly fruitful avenue for further translation process research.

\section{References}

Anderson, M. 2003. Ethnography as translation. In: Petrilli, S. (ed.) Translation Translation. Amsterdam: Rodopi. 389-398.

Angelone, E. 2009. Beyond TAPs: a dual-mode methodology for assessing uncertainty management processes. Paper presented at the $3^{\text {rd }}$ IATIS Conference, Melbourne, Australia. Blommaert, J. 2005. Bourdieu the ethnographer: the ethnographic grounding of habitus and voice. In: Inghilleri, M. (ed.) Bourdieu and the Sociology of Translation and Interpreting. The Translator Vol. 11. No. 2. 219-236.

Bourdieu, P. 1986. Distinction: A Social Critique of the Judgment of Taste. London: Routledge.

Buzelin, H. 2004. La traductologie, l'ethnographie et la production des connaissances. [Translation Studies, ethnography and knowledge production]. Meta Vol. 49. No. 4. 729746.

Buzelin, H. 2007a. Translations 'in the making'. In: Wolf, M. \& Fukari, A. (eds.) Constructing a Sociology of Translation. Amsterdam and Philadelphia: John Benjamins Publishing Company. 135-169.

Buzelin, H. 2007b. Translation Studies, ethnography and the production of knowledge. In: St.

Pierre, P. \& Kar, P.C. (eds.) Translation: Reflections, Refractions, Transformations. Amsterdam and Philadelphia: John Benjamins Publishing Company. 39-56.

Charmaz, K. 2006. Constructing Grounded Theory - A Practical Guide Through Qualitative Analysis. London: Sage Publications.

Chesterman, A. 2007. Bridge concepts in translation sociology. In: M. Wolf \& Fukari, A. (eds.) Constructing a Sociology of Translation. Amsterdam and Philadelphia: John Benjamins Publishing Company. 171-183. 
Englund Dimitrova, B. 2005. Expertise and Explicitation in the Translation Process. Amsterdam and Philadelphia: John Benjamins Publishing Company.

Fabian, J. 2002. Virtual Archives and Ethnographic Writing. 'Commentary’ as a New Genre? Current Anthropology Vol. 43. No. 5. 775-786.

Fraser, J. 2000. What do real translators do? Developing the use of TAPs from professional translators. In: Jääskeläinen, R. \& Tirkkonen-Condit, S. (eds.) Tapping and Mapping the Processes of Translation and Interpreting. Amsterdam: John Benjamins Publishing Company. 111-123.

Gambier, Y. 2007. Y a-t-il place pour une socio-traductologie? In: M. Wolf \& Fukari, A. (eds.) Constructing a Sociology of Translation. Amsterdam and Philadelphia: John Benjamins Publishing Company. 205-217.

Glaser, B. \& Strauss, A. 1967. The Discovery of Grounded Theory: Strategies for Qualitative Research. Chicago: Aldine.

Goffman, E. 1968. Asylums: Essays on the Social Situation of Mental Patients and Other Inmates. Harmondsworth: Penguin.

Gold, R. 1958. Roles in social fieldwork. Social Forces Vol. 36. 217-23.

Hammersley, M. \& Atkinson, P. 2007. Ethnography. New York: Routledge.

Hansen, G. 2005. Experience and emotion in empirical translation research with think-aloud and retrospection. Meta Vol. 50. No. 2. 511-521.

Hansen, G. 2008. The dialogue in translation process research. Paper presented at the XVIII FIT World Congress, Shanghai, China.

Hansen, G., Chesterman, A. \& Gerzymisch-Arbogast, H. (eds.) 2009. Efforts and Models in Interpreting and Translation Research: a Tribute to Daniel Gile. Amsterdam and Philadelphia: John Benjamins Publishing Company.

Hermans, T. (ed.) 2002. Crosscultural Transgressions. Research Models in Translation Studies 2: Historical and Ideological Issues. Manchester: St. Jerome Publishing.

Hermans, T. 2007. Translation, irritation and resonance. In: Wolf, M. \& Fukari, A. (eds.) Constructing a Sociology of Translation. Amsterdam and Philadelphia: John Benjamins Publishing Company. 57-75.

Herzfeld, M. 2003. The unspeakable in pursuit of the ineffable: representations of untranslatability in ethnographic discourse. In: Rubel, P. \& Rosman, A. (eds.) Translating Cultures - Perspectives on Translation and Anthropology. 109-134.

House, J. 2000. Consciousness and the strategic use of aids in translation. In: Jääskeläinen, R. \& Tirkkonen-Condit, S. (eds.) Tapping and Mapping the Processes of Translation and Interpreting. Amsterdam: John Benjamins Publishing Company. 149-163. 
Immonen, S. 2009. Unraveling the processing units of translation. Paper given at the conference Translation Studies: Moving In - Moving On, University of Joensuu, Finland. Inghilleri, M. 2003. Habitus, Field and Discourse: Interpreting as a Socially Situated Activity. Target Vol. 15. No. 2. 243-68.

Inghilleri, M. (ed.) 2005. Bourdieu and the Sociology of Translation and Interpreting. The Translator Vol. 11. No. 2.

Jääskeläinen, R. 1999. Tapping the Process: An Explorative Study of the Cognitive and Affective Factors Involved in Translating. Joensuu: University of Joensuu.

Jääskeläinen, R. \& Tirkkonen-Condit, S. (eds.) 2000. Tapping and Mapping the Processes of Translation and Interpreting. Amsterdam: John Benjamins Publishing Company.

Jakobsen, A. L. 2003. Effects of think aloud on translation speed, revision and segmentation.

In: Alves, F. (ed.) Triangulating Translation: Perspectives in Process Oriented Research. Amsterdam: John Benjamins Publishing Company. 69-96.

Jakobsen, A. L. 2009. Plenary speech given at the conference Translation Studies: Moving In - Moving On, University of Joensuu, Finland.

Junker, B. 1960. Field Work. Chicago: University of Chicago Press.

Kant, I. 1781/1929. The Critique of Pure Reason. New York: St. Martin's Press.

Koskinen, K. 2006. Going into the field: ethnographic methods in Translation Studies. In: Wolf, M. Übersetzen - translating - traduire: towards a 'social turn'? 109-118.

Koskinen, K. 2008. Translating Institutions: an Ethnographic Study of EU Translation. Manchester: St. Jerome Publishing.

Laukkanen, J. 1996. Affective and attitudinal factors in translation processes. Target Vol. 8. No. 2. 257-274.

Li, D. 2004. Trustworthiness of think-aloud protocols in the study of translation processes. International Journal of Applied Linguistics Vol. 14. No. 3. 301-313.

Linke, M. 2008. A Cognitive Approach to Equivalence in Literary Translation - Illustrated by an Analysis of Images of Women in Henry James's Portrait of a Lady and its Polish Translation Portret Damy. Torun: Wydawn.

Maryns, K. 2004. The Asylum Speaker: An Ethnography of Language and Communication in the Belgian Asylum Procedure. Unpublished PhD Dissertation. Ghent: Ghent University.

Papavassiliou, P. 2007. Traductologie et sciences cognitives: une dialectique prometteuse. Meta Vol. 52. No. 1. 29-36.

Rubel, P. \& Rosman, A. (eds.) 2003. Translating Cultures - Perspectives on Translation and Anthropology. Oxford: Berg. 
Saler, B. 2003. The ethnographer as pontifex. In: Rubel, P. \& Rosman, A. (eds.) Translating Cultures - Perspectives on Translation and Anthropology. 197-212.

Séguinot, C. 2000. Management Issues in the Translation Process. In: Jääskeläinen, R. \& Tirkkonen-Condit, S. (eds.) Tapping and Mapping the Processes of Translation and Interpreting. Amsterdam: John Benjamins Publishing Company. 143-149.

Snow, D. 1999. Assessing the ways in which qualitative/ethnographic research contributes to social psychology: introduction to the special issue. Social Psychology Quarterly Vol. 62. No. 2. 97-100.

Sturge, K. 1997. Translation Strategies in Ethnography. The Translator Vol. 3. No. 1. 21-38.

Sturge, K. 2006. The Other on Display: Translation in the Ethnographic Museum. In Hermans, T. (ed.) Translating Others (vol. 2). Manchester: St Jerome Publishing. 431-40.

Sturge, K. 2007. Representing Others: Translation, Ethnography and the Museum. Manchester: St Jerome Publishing.

Tirkkonen-Condit, S. 1997. Who verbalises what: a linguistic analysis of TAP texts. Target Vol. 9. No. 1. 69-84.

Tirkkonen-Condit, S., Mäkisalo, J. \& Immonen, S. 2008. The translation process - interplay between literal rendering and a search for sense. Across Languages and Cultures Vol. 9. No. 1. 1-15.

Tirkkonen-Condit, S. 2009. Translation prototype and how to exploit it in translator education. Plenary speech given at the conference Translation Studies: Moving In Moving On, University of Joensuu, Finland.

Tymoczko, M. 2007. Enlarging Translation, Empowering Translators. Manchester: St Jerome Publishing.

Valero-Garcés, C. 1995. Modes of translating culture: ethnography and translation. In: Mejri, S. \& Baccouche, T. (eds.) La traduction dans le monde arabe Vol. 40. No. 4. 556-563.

Wilss, W. 1996. Knowledge and Skills in Translator Behavior. Amsterdam and Philadelphia: John Benjamins Publishing Company.

Wolf, M. 1997. Translation as a process of power: aspects of cultural anthropology in translation. In: Snell-Hornby, M., Jettmarová, Z. \& Kaindl, K. (eds.) Translation as Intercultural Communication. Amsterdam and Philadelphia: John Benjamins Publishing Company. 123-133.

Wolf, M. 2002. Culture as translation - and beyond: ethnographic models of representation in Translation Studies. In: Hermans, T. (ed.) Crosscultural Transgressions. Research 
Models in Translation Studies 2: Historical and Ideological Issues. Manchester: St. Jerome Publishing. 180-192.

Wolf, M. \& Fukari, A. (eds.) 2007. Constructing a Sociology of Translation. Amsterdam and Philadelphia: John Benjamins Publishing Company. 